Arq. Leonardo Ramos Monori Proyectista.

Universidad de Cuenca

Recibido: 15 de febrero 2012 Aceptado: 15 de Marzo 2012

\section{Enlargement Project and readjustment of the Faculty of Architecture and Urbanism of the Cuenca University, Building of Post-degree}

\section{Resumen}

Las nuevas circunstancias de la política académica institucional, la superación de la falta de dotación del número de aulas para cubrir las actuales necesidades, racionalizar asignaciones y horarios, y la mayor dotación de cubículos para fines de investigación y labores vinculadas a la docencia para un mayor número de catedráticos, motiva a la Facultad de Arquitectura y Urbanismo de la Universidad de Cuenca en el año 2007 a proponer la ampliación de su infraestructura. El presente artículo ha sido preparado en base a la memoria técnica presentada y que resultó ganadora en el concurso. En el mismo se muestra la intención del diseñador y las consideraciones que se tuvieron tanto para la construcción del nuevo edificio, como algunas de las readecuaciones en los edificios existentes que fueron integradas a la propuesta.

Palabras clave: Proyecto, ampliación, adecuación, Cuenca, Facultad de arquitectura

\begin{abstract}
:
The new circumstances of the institutional academic politic, the overcoming of the lack of provision of number of classrooms to meet the current needs, streamline assignments and schedules, and the larger envelope of cubicles to research purposes and works related to teaching for a greater number of professors, encourage the Faculty of Architecture and Urbanism of the University of Cuenca in $\mathbf{2 0 0 7}$ to propose the extension of its infrastructure. This article has been prepared based on the technical report submitted and resulting winner in the contest. It shows the designer's intention and the considerations that prompted both for the construction of the new building, as some of the retrofits in existing buildings which were integrated to the proposal.
\end{abstract}

Keywords: Project, extension, adjustment, Cuenca, Faculty of architecture 


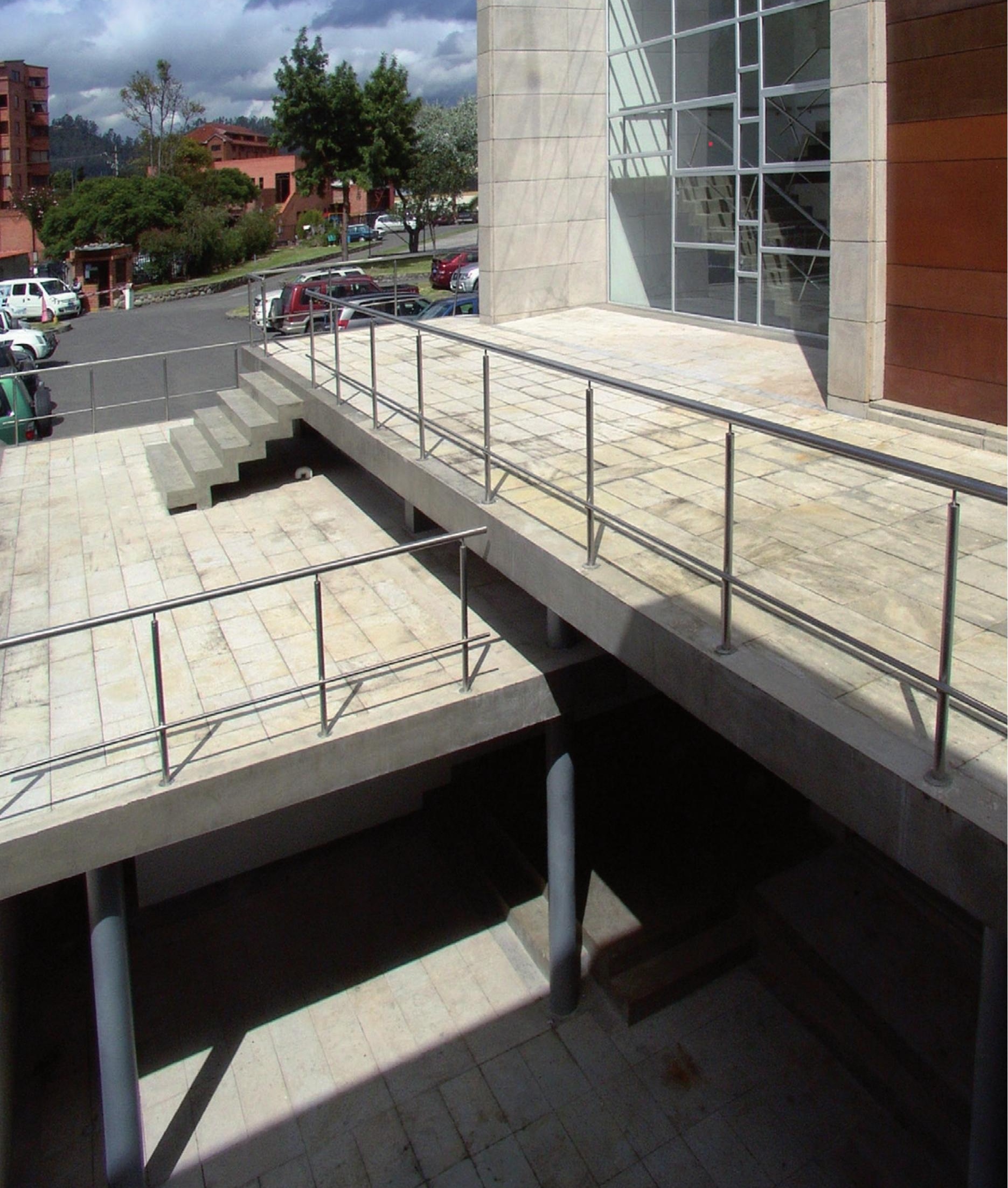


Memoria: Proyecto de ampliación y readecuación de la Facultad de Arquitectura...

\section{Introducción:}

En el año 2007 se realizó el llamamiento a un concurso interno para la intervención y ampliación de las instalaciones de la Facultad de Arquitectura y Urbanismo de la Universidad de Cuenca. Se presentaron diez propuestas, siendo ésta la triunfadora.

Entre los objetivos principales de la propuesta estaba el mantener la vigencia conceptual que generó el mencionado edificio, la lectura comprensible entre la arquitectura existente y la incorporada, la posibilidad de una articulación coherente y versátil entre arquitectura existente y nueva y la evolución cualitativa que permita la adaptabilidad, lo cual obligaba a ser discreto en la solución arquitectónica, en un planteamiento funcional y económico; elementos que se explican en el desarrollo del presente artículo.

\section{Propuesta:}

En el concurso no se precisó el sitio, por lo que la primera decisión en torno al proyecto fue la elección del lugar. El sitio elegido, en el que se emplaza el Centro de Postgrado de la Facultad de Arquitectura es un terreno regular de aproximadamente 15 $\mathrm{m}$ de lado, ubicado entre el bloque $\mathrm{B}$ y el bloque $\mathrm{C}$ al final de la calle, junto al taller de carpintería existente.

Se ocupa todo el terreno disponible, alterando mínimamente la zona de parqueaderos de estudiantes, proyectándose un bloque de base cuadrada, cuyo eje de simetría coincide con el de la calle, manteniendo la alineación Este-Oeste, hacia el cual se orienta el acceso. El eje compositivo o calle, estructura los flujos y la organización de los edificios. (Imagen 1-2)

Este edificio abarca el área de Postgrado e Informática. En la planta de subsuelo se sitúa el Centro de Cómputo con oficinas para su dirección y aulas de audiovisuales. En la planta baja se ubican las oficinas de la Dirección de las Maestrías. En la primera, segunda y tercera plantas altas se disponen los cubículos para los profesores y las aulas de talleres audiovisuales y de trabajo para la zona de las maestrías. Cabe señalar que se tiene previsto el funcionamiento de tres maestrías permanentes que se realizan una semana cada mes de los ciclos lectivos.

Tanto la planta baja como la del subsuelo del nuevo edificio están al mismo nivel que la planta baja, el subsuelo de la carpintería y el bloque $B$, por donde se realizan las interconexiones.

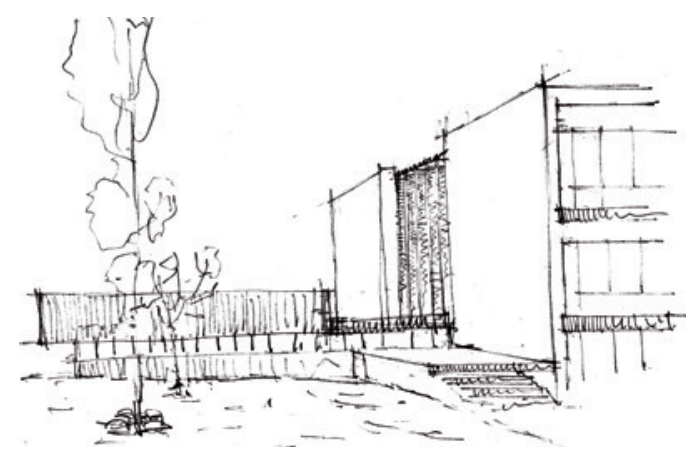

1

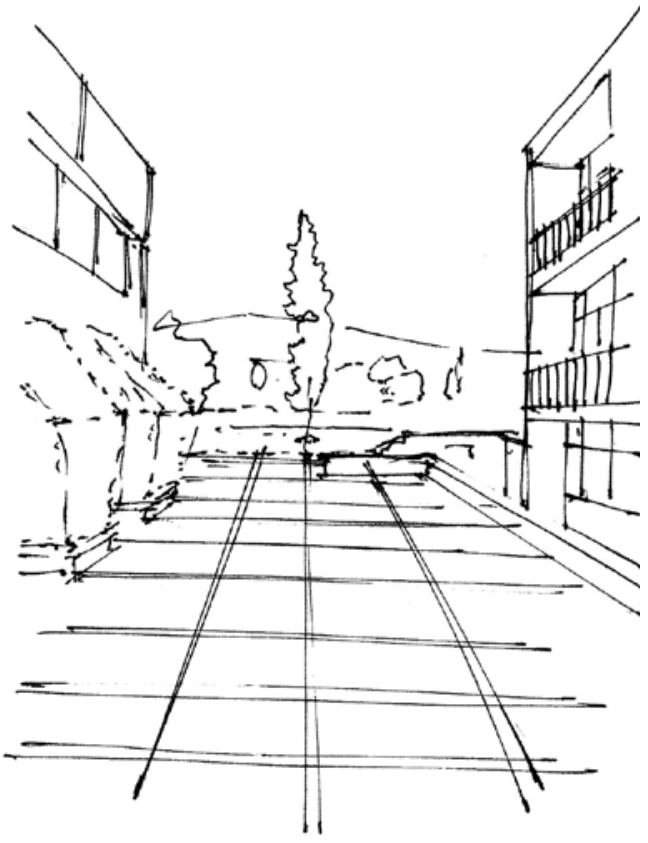




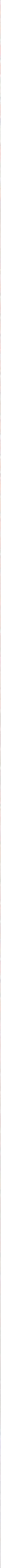


Memoria: Proyecto de ampliación y readecuación de la Facultad de Arquitectura...

El problema principal estuvo en rellenar el vacío que se produce entre el bloque $\mathrm{B}$ y el proyectado, en donde suelen hacerse visibles todos los errores que puedan ocurrir entre uno y otro. Para resolver los posibles desplomos, desalineamientos y desniveles que se pudieran presentar, se recurre a la losa de cubierta de la carpintería, espacio abandonado de aproximadamente $250 \mathrm{~m} 2$, donde se genera una plazoleta; espacio exterior que es considerado un lugar de trabajo y de reflexión y que permite activar ciertas situaciones elementales como las de estudiar, conversar, leer, comer o llamar por teléfono y también apreciar del paisaje de El Cajas, el campus y el Centro Histórico de la ciudad.

Este núcleo resuelve además un problema topológico que presentaba la planta, puesto que todas las circulaciones tenían que converger hacia ese punto, lo que hace posible el paso a través del bloque $B$ hacia la edificación proyectada.

En lugar de salpicar al conjunto con un elemento aislado más, se propuso que la nueva edificación se disolviera en lo existente, a través de este núcleo, para que tres elementos conformaran uno que permitiera articular de forma coherente y versátil la arquitectura nueva y la existente. (Imagen 3-4-5)

La implantación y concreción del bloque está relacionada con saber aprovechar circunstancias que a primera vista parecen desventajas, pero que en realidad no lo son.

En la resolución del aspecto estético y material, y al momento de establecer vínculos con el conjunto arquitectónico, éste proporcionó elementos que intervinieron en el sistema formal y le dieron sentido arquitectónico y urbano a la propuesta. El edificio fue estructurado por vínculos de relación visual, de modo que la coherencia no se alcance por armonía, sino por equilibrio de los distintos componentes que intervienen en el episodio arquitectónico.

El proyecto es de una rigurosa economía formal, proponiéndose un cerramiento hacia la esfera pública universitaria y una apertura hacia la calle.

La volumetría abstracta se relaciona con el conjunto debido a las proporciones que se manejan en los planos de las fachadas. Los muros ciegos determinan cierta condición introvertida al edificio que responde a la intención de dotarlo de una fuerza equiparable al trabajo concentrado.

El tratamiento sobrio del volumen es únicamente alterado por la sustracción hecha para el ingreso al edificio. (Imagen 6-7)

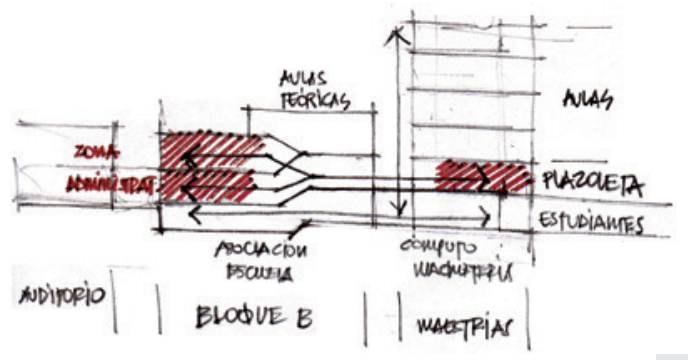

3

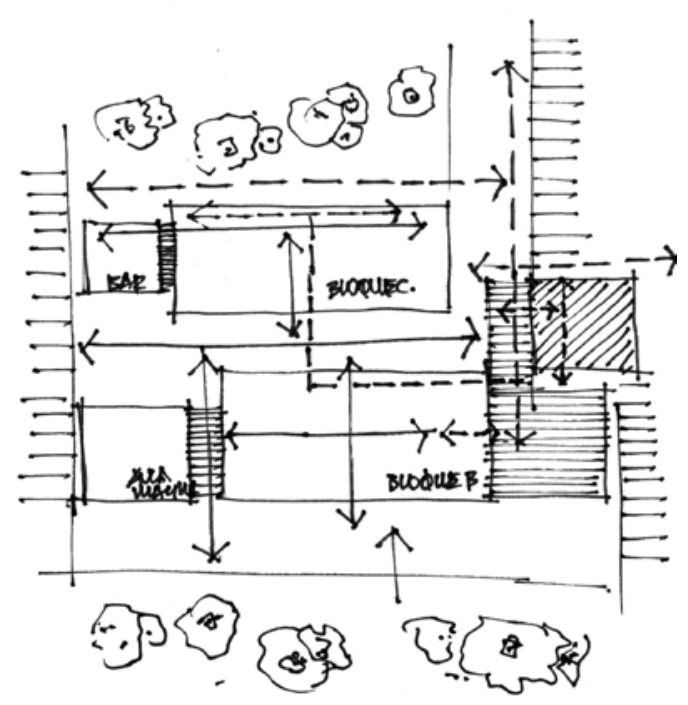

4
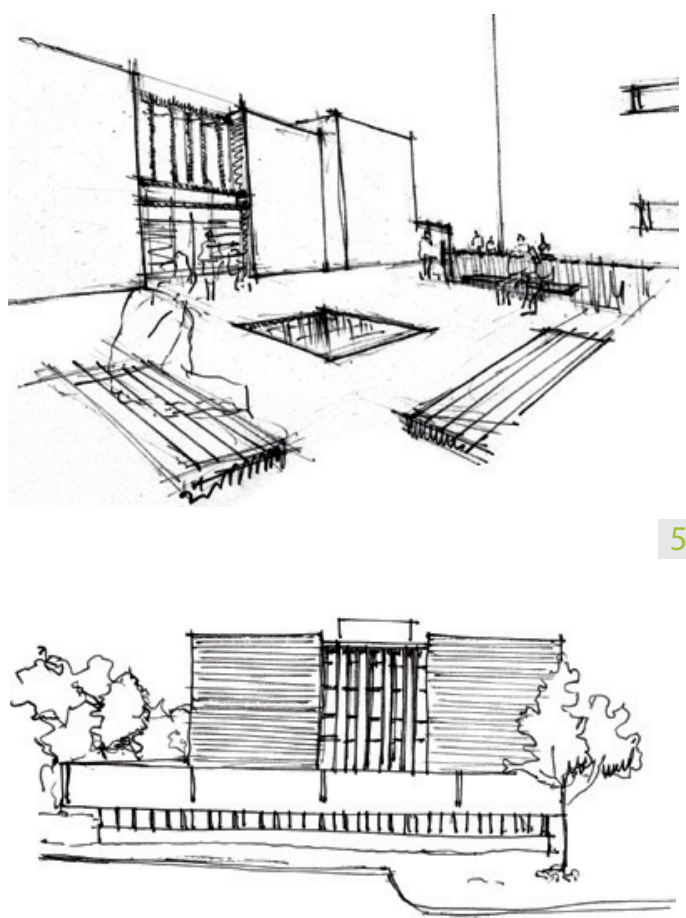


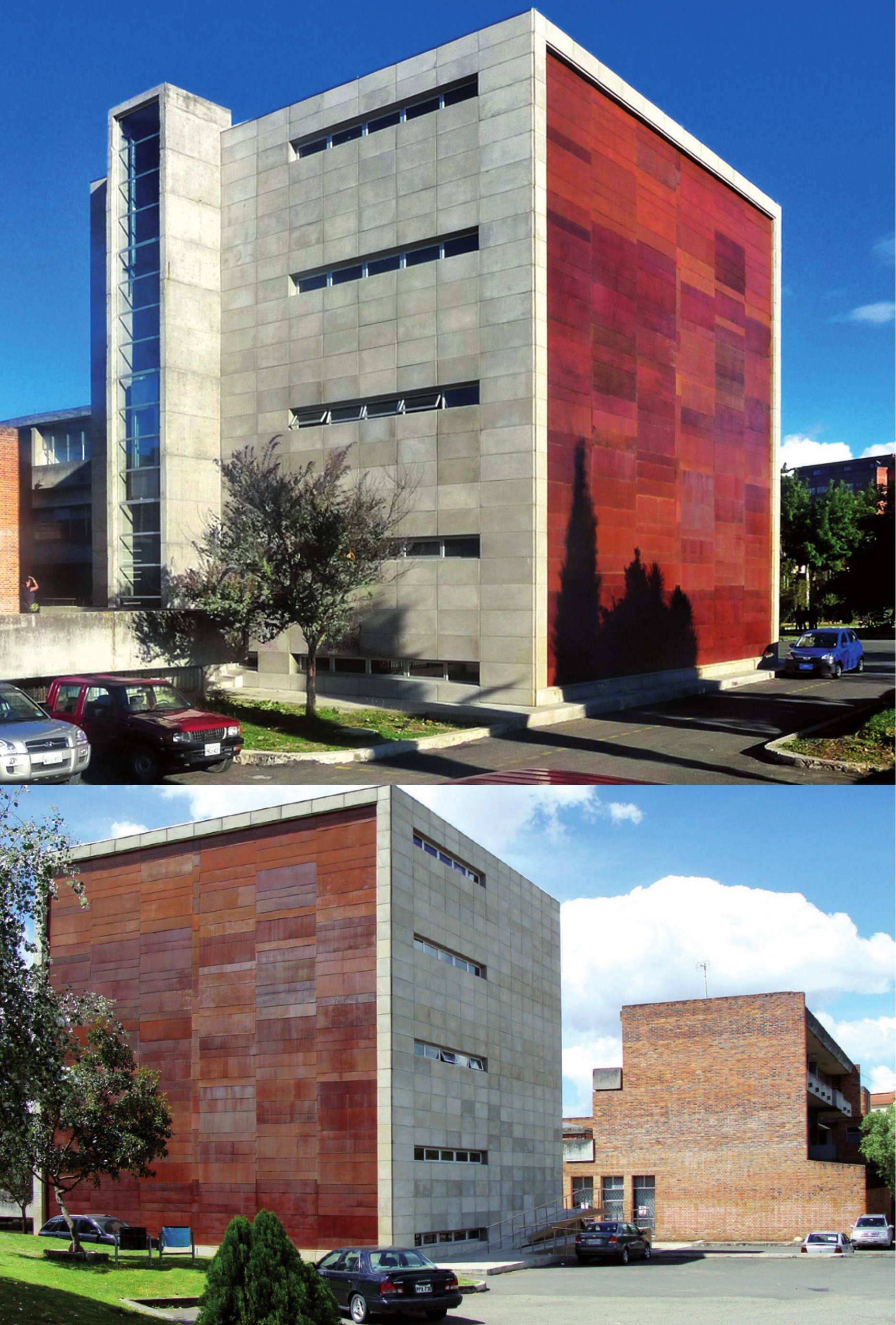


La alineación Este-Oeste de la calle ofrecía la posibilidad de una perspectiva frontal que desembocaba en un árbol de eucalipto, generando una continuidad visual entre la línea del eje de la calle y la línea natural que ofrecía el eucalipto. Para conservar esa continuidad visual se hace uso de la abstracción manteniendo así el diálogo con la memoria de esa preexistencia natural.

Por lo tanto, cualquier énfasis jerárquico tenía que ocurrir en el sentido de la circulación larga; así, el eje compositivo de la calle coincide con el eje de simetría del edificio, cuya estructura es de hormigón armado. (Imagen 8)

La unidad de la fachada Este de la nueva edificación se resolvió sin recurrir a la complejidad, sino más bien respetando las cualidades formales de los dos edificios existentes de los años setenta, que eran bastante correctos. Parecía razonable proyectarla como dos planos simétricos recubiertos el uno de vidrio, donde se ubica el acceso, la escalera plisada de hormigón armado y los vestíbulos; y el otro de acero tipo cortén, donde se ubican los cubículos y los baños. De esta forma se marcaba una línea que le daba jerarquía a la fachada.

En la fachada Oeste, revestida de láminas de acero tipo cortén, era posible independizarse un poco más del contexto del campus; se proyectó una fachada ligera, multicapa y montada en seco que permitía un aislamiento acústico con el estadio universitario. Tanto en la fachada Este como en la Oeste, la textura, el color y la posición de cada elemento fue determinada al azar, se aplicó la sucesión de Fibonacci por la búsqueda de un tipo de orden que no quedara identificado con regularidad, que siguiera unas leyes que no fueran demasiado obvias, para así mantener una relación visual con la textura, el color y la forma de aparejamiento del ladrillo de las edificaciones existentes. (Imagen 9-10)

Las fachadas Norte y Sur fueron recubiertas íntegramente por paneles de hormigón prefabricado, sustentados por una estructura metálica auxiliar. En la fachada Norte se ubica un ascensor tipo panorámico, su estructura es de muro portante de hormigón armado, cuya geometría y proporción mantiene un ritmo visual con los vanos alargados de la fachada Este del bloque B existente. Además de cumplir con la función de conector vertical se aprovecha para el deleite del paisaje tanto del campus universitario como de El Barranco y el Centro Histórico de la ciudad. (Imagen 11)

Tal vez en la elección de los elementos superficiales, conjuntamente con la junta de los paneles de hormigón y el traslape de las planchas de acero tipo cortén, esté uno de los aspectos más significativos, ya que los mismos determinaron el acabado final de la fachada, imponiendo con esta elección, una textura y un orden acorde con el proyecto.
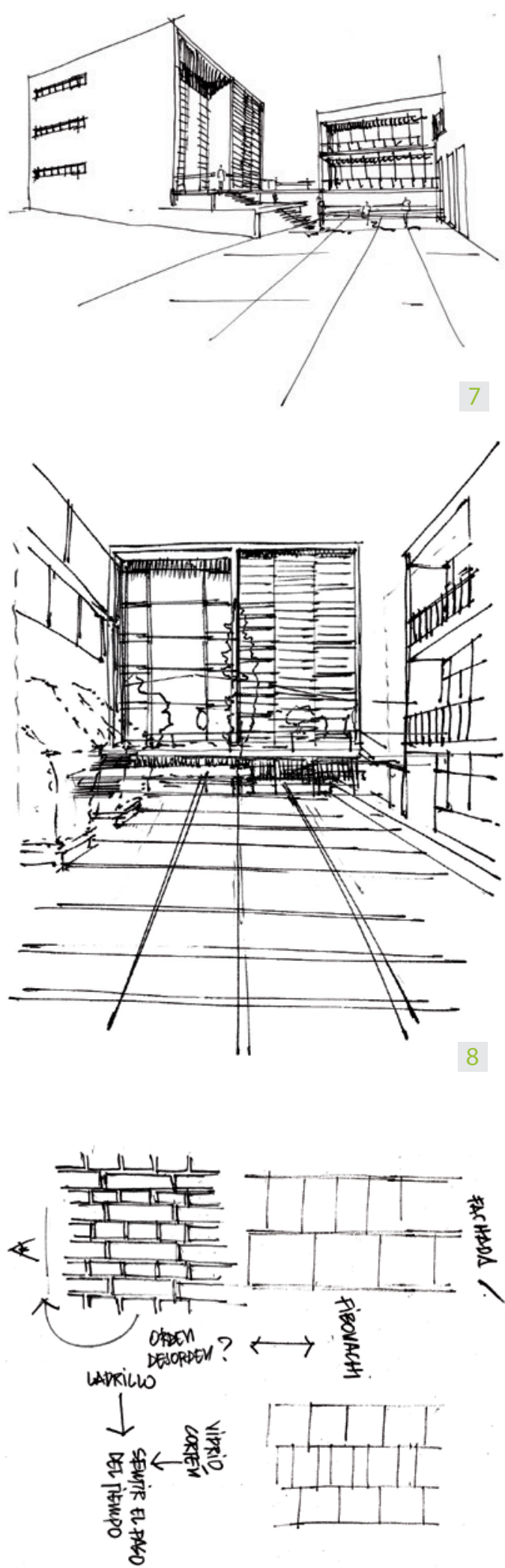

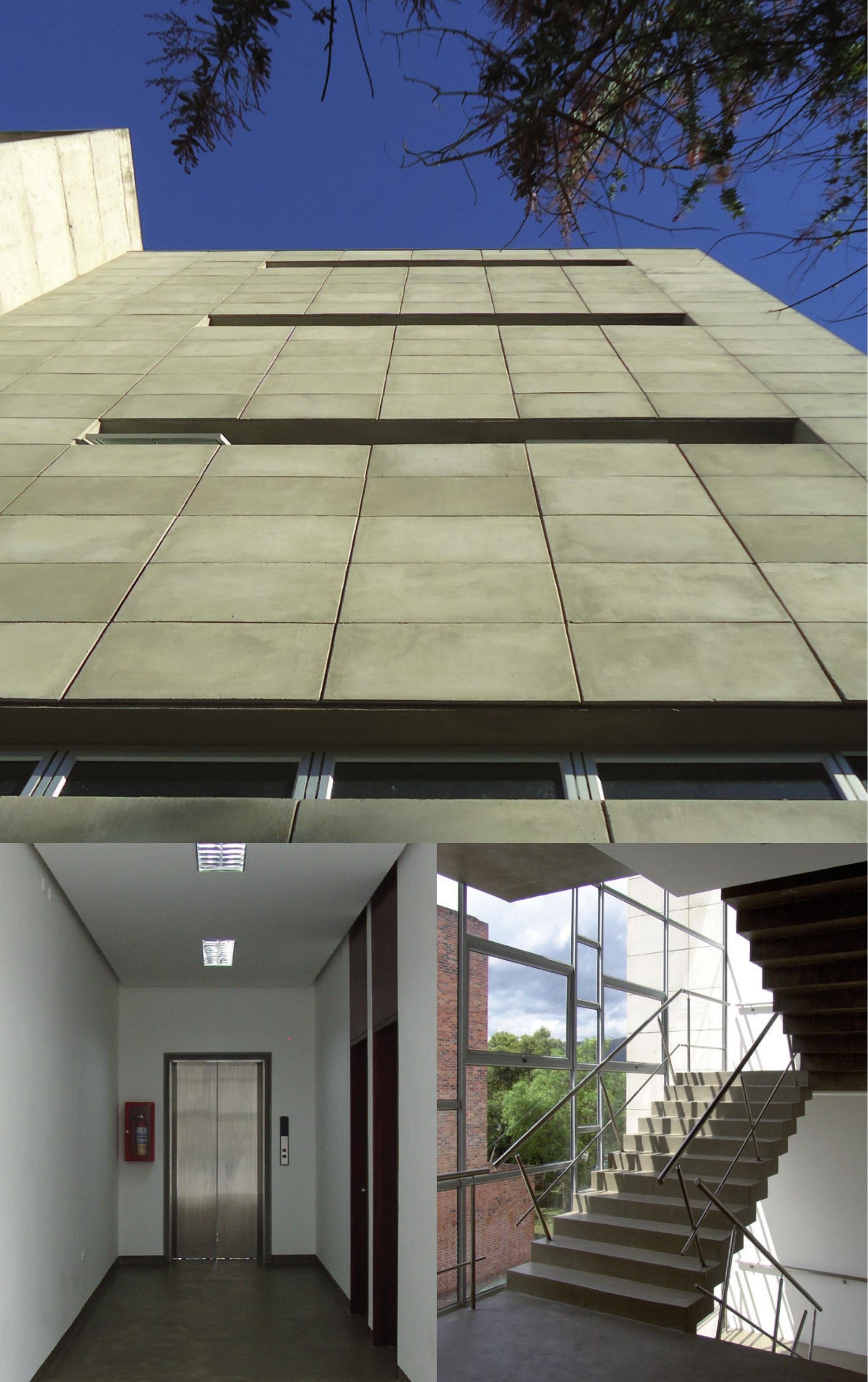
La selección de materiales contemporáneos como el hormigón y el acero tipo cortén obedece a su naturalidad y a su autenticidad, cuya característica es la de "sentir" el paso del tiempo; lo que acontece con el ladrillo y el hormigón presentes en las edificaciones existentes, con lo que se logra un equilibrio visual de textura y color, y la integración estética y arquitectónica al conjunto.

La elección del material fija una continuidad visual, continuidad que con el paso del tiempo será aún más evidente.

En la fachada Este del edificio se abrió un vacío recubierto de vidrio que amplía la conversación con la calle, los balcones y las terrazas propuestas. Espacios como éstos facilitan los encuentros y los diálogos casuales y constituyen el complemento perfecto de las aulas del trabajo concentrado y en solitario.

Para la definición al interior del edificio se recurrió a la monocromía absoluta en suelos, cielos rasos y paredes, complementándose con los muebles y la tabiquería, es decir, el contraste en el espacio se da con el mobiliario predominando el blanco y el crudo. El blanco es un color con una amplia gama de subtonos capaces de resaltar la arquitectura que se quiere alcanzar.

El cielo raso está exento de las paredes para dar la sensación de que se encuentra levitando. El tratamiento del piso es en base de microcemento color natural con la barredera rehundida para dar el mismo efecto con la pared. En la solución de los encuentros entre materiales y elementos arquitectónicos siempre existe un espacio de transición. (Imagen 12)

La escalera plisada de hormigón armado es un elemento escultural en alusión a las escaleras de los edificios existentes, que ayuda a mantener la continuidad espacial y visual de la calle y además cumple las funciones de globalizador y conector. (Imagen 13)

Cabe destacar que el edificio se diseñó pensando en la accesibilidad de las personas con discapacidad física, proyectándose un ascensor y un sistema de rampas tanto para el edificio como para las edificaciones existentes en lo que se refiere a las conexiones; logrando así una accesibilidad del $100 \%$ a la nueva edificación y el $75 \%$ de los dos edificios existentes.

A nivel de conjunto, el subsuelo es de uso estudiantil, en donde se rehabilita el taller de maquetería y carpintería haciendo que las circulaciones de los tres bloques confluyan en él. Sector en donde se ubican además el Centro de Cómputo (edificio nuevo) y el área de la Asociación
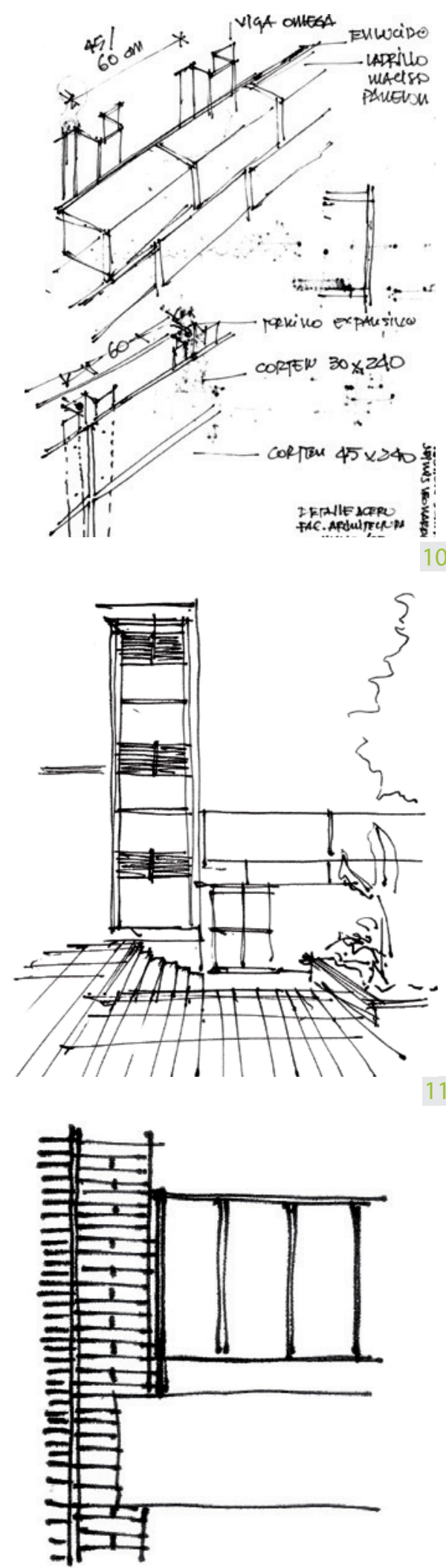

Escuela de Arquitectura con sus respectivas oficinas, una sala de reuniones común y un aula de uso múltiple para realizar tareas extracurriculares (bloque B), integrando así estudio-investigación-cultura-recreación.

Se genera además una plazoleta hacia el exterior en el vacío que sirve de acceso a la imprenta la misma que es reubicada, para permitir la conexión a nivel de subsuelo del bloque $C$ hacia el bloque $B$, el taller de maquetería y carpintería y la edificación nueva. Esta área es destinada también a parqueadero de bicicletas.

El bloque $B$ se destina a aulas teóricas en la última planta y talleres en las demás plantas. En éste se ubican las aulas de apoyo.

El bloque $\mathrm{C}$ se destina exclusivamente a talleres. $\mathrm{A}$ nivel de planta baja se libera la escalera con un criterio que destaca a la estructura original del edificio y coadyuva a mantener una correcta relación entre vestíbulo y sala de exposiciones. Además se proyectan aulas de expresión gráfica, las mismas que son orientadas hacia el jardín Sur. (Imagen 14)

El área administrativa ocupa el actual local y además el espacio de la antigua biblioteca para tener un vínculo directo entre Secretaría General y Administrativa a través de la circulación vertical generada por la grada de acceso a la antigua biblioteca. En el espacio del antiguo decanato se proyectan la sala de atención a estudiantes, y en el lugar de la antigua Secretaría General, la Sala de Profesores con espacios de trabajo.

Se concibe un amplio vestíbulo a la salida del Aula Magna con la incorporación de puertas de vidrio en los dos vacíos existentes en conexión con el bloque B, logrando una relación directa con el vestíbulo de dicho bloque.

Con el propósito de propiciar los encuentros, las conversaciones casuales y la revitalización de los espacios exteriores, se realiza la intervención de los mismos, se rediseñan las plazoletas existentes, se crean plazoletas entre el bloque del bar y el Aula Magna y en el jardín Sur, poniéndose énfasis en el diseño para personas con discapacidad física, generándose también parqueaderos para discapacitados.
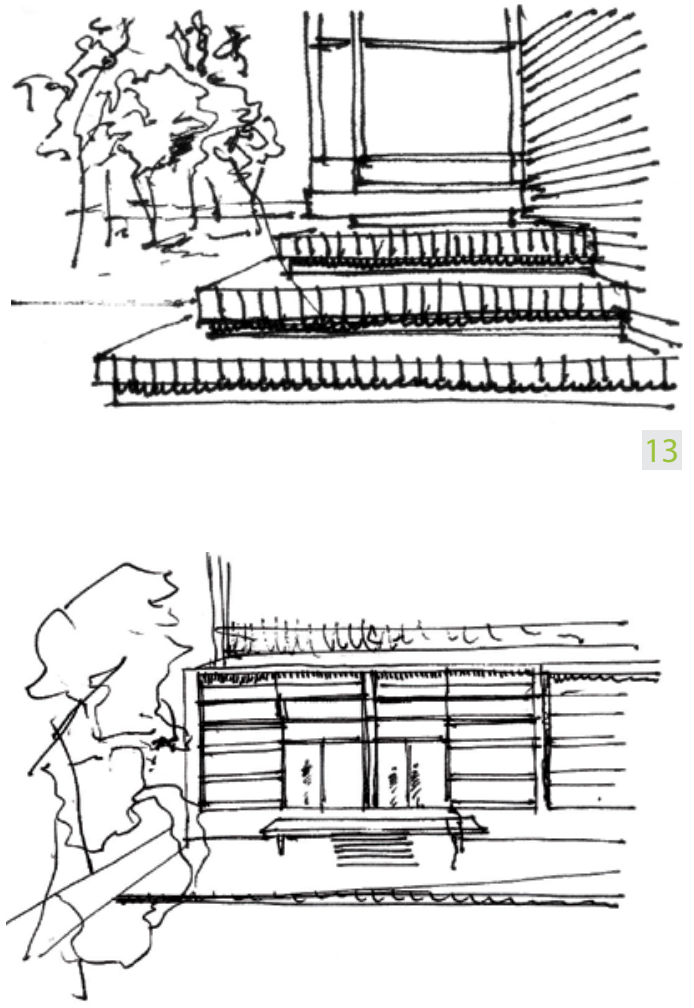


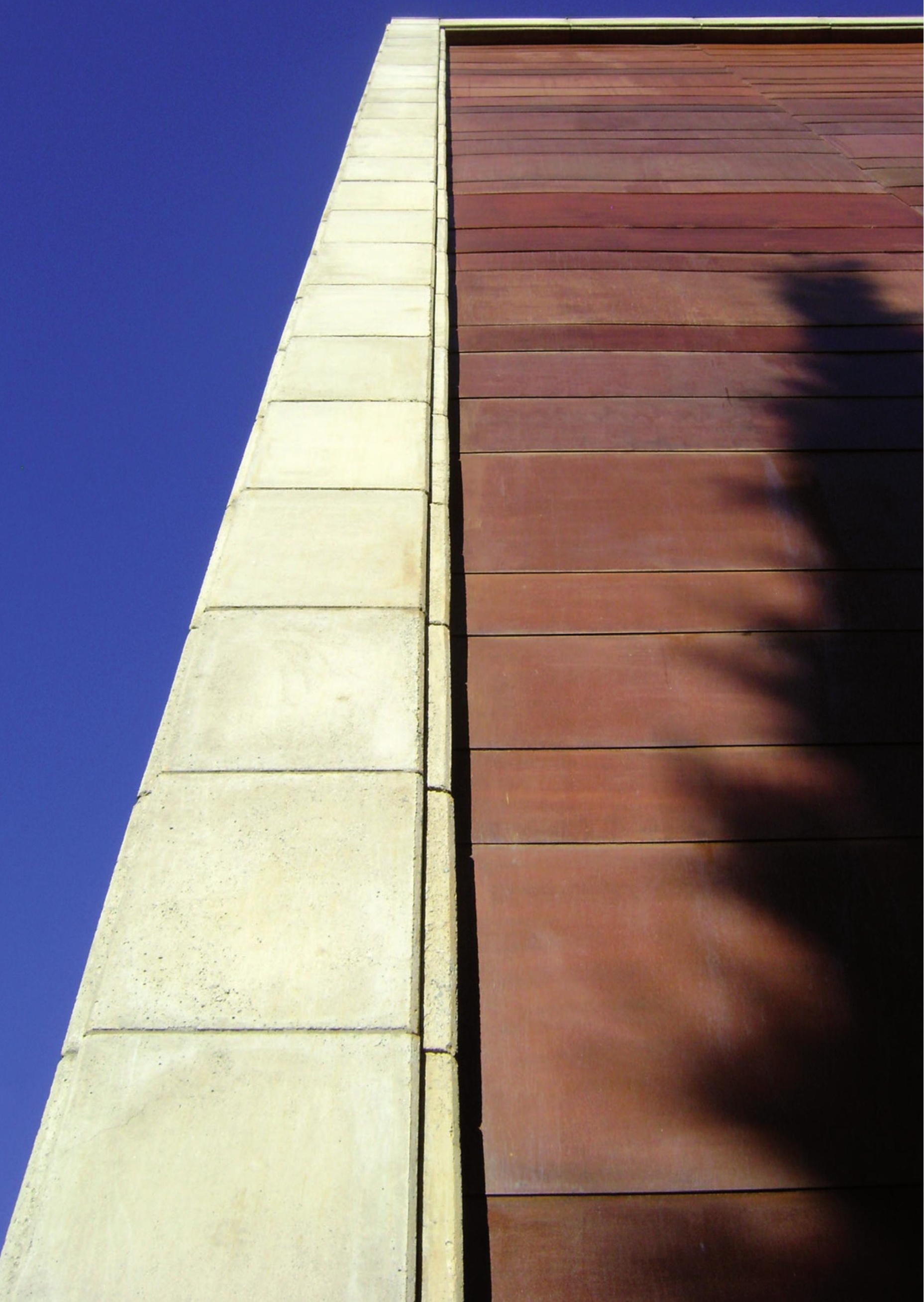




\section{Imágenes}

1 a 14 Arq. Leonardo Ramos Monori

Pag. 12 inferior Arq. Leonardo Ramos Monori

Fotografías

Pag. 4 y 6 DUAL

Pag. 8 superior Daniela Auquilla / inferior Arq. Leonardo Ramos Monori

Pag. 10 superior Grace Merchán / inferior DUAL

Pag. 12 superior Jose Luis Chauca

Pag. 14 Melinton Pulla 